\section{Au-Fe system: application in electro-catalysis}

\section{Malaknaz Mirdamadi-Esfahani ${ }^{1}$, Mehran Mostafavi ${ }^{1}$, Bineta Keita ${ }^{1}$, Louis Nadjo', Patricia Kooyman², Arnaud Etcheberry ${ }^{3}$, Marianne Imperor ${ }^{4}$, Hynd Remita ${ }^{*}$}

1 Laboratoire de Chimie Physique, Bât. 349-350, UMR 8000-CNRS, Université Paris XI, F- 91405 Orsay, France, E-mail : hynd.remita@lcp.u-psud.fr

2 DelftChemTech and National Centre for HREM, Delft University of Technology, Julianalaan 136, 2628 BL Delft, The Netherlands

3 IREM-Institut Lavoisier, 45 rue des Etats-Unis, UMR 8637-CNRS, Université Versailles Saint-Quentin-enYvelines, 78035 Versailles Cedex, France

4 Laboratoire de Physique des Solides, UMR 8502 CNRS, Bât 510, Université Paris XI, 91405 Orsay, France

\begin{abstract}
Radiolytic reduction of mixed Au'"'/Fe" ethylene glycol solutions led to two kinds of particles: $2 \mathrm{~nm}$ Fe rich nanoparticles as well as large rods (a few tens of $\mathrm{nm}$ ) and faceted particles rich in gold and containing a small amount of iron. The adjunction of iron to gold enhances remarkably its electro-catalytic properties toward oxygen and proton reduction. Our results show that Au-Fe system is very promising for application in fuel cells.
\end{abstract}

\section{Keywords}

Gold, Iron, Nanoparticles, Radiolysis, Fuel cells, Oxygen reduction, Hydrogen reduction.

\section{Introduction}

Gold-based nanoparticles have recently emerged as highly active catalysts for many important catalytic reactions, mostly oxidation processes such as CO or methanol oxidation, ${ }^{1-4}$ and oxygen reduction ${ }^{5}$. A major factor for the catalytic activity is related to the size and composition-dependent structural properties of the nanoparticles.

Au-based solids have been studied as potential electrocatalysts for fuel cell applications, in the oxidation of hydrogen and $\mathrm{CO}^{6-9}$ and that of alcohols. ${ }^{10,11}$ They are also efficient for the oxygen reduction reaction (ORR). ${ }^{12,13}$ Recently it has been reported that carbon supported Pt-Au bimetallic nanoparticles display better or similar performances to those of pure platinum supported on carbon for oxygen reduction. ${ }^{14,15}$

The association of gold with iron can be interesting in the fields of catalysis and electro-catalysis and for biomedical application. To our knowledge, the reported attempts concerning chemical synthesis of alloyed Au-Fe nanoparticles were in general unsuccessful because of a systematic segregation between gold and iron. Au-Fe colloidal dispersions were not described so far, except when supported on substrates. ${ }^{16,17,18}$ However, recently, Au-Fe monodisperse nanoparticles were synthesized by reduction of gold acetate by 1,2-hexadecanediol and the thermal decomposition of iron pentacarbonyl in the presence of the stabilizers oleic acid and oleylamine. ${ }^{19}$ Here, we synthesize the Au-Fe system by radiolytic reduction and show that the obtained material exhibits a high electro-catalytic efficiency both for proton reduction and oxygen reduction.

Radiolytic reduction of metal ions in solutions is an efficient process to synthesize bimetallic nanoparticles of controlled size and structure. ${ }^{20,21}$ Different bimetallic nanoparticles have been synthesized by radiolysis as core-shells or alloyed depending on the dose rate such as: $\mathrm{Au}-\mathrm{Ag},{ }^{22} \mathrm{Au}-\mathrm{Pd},{ }^{23} \mathrm{Au}-\mathrm{Pt},{ }^{24}$ $\mathrm{Ag}-\mathrm{Pd}^{25} \ldots$ The hydrated electrons and the reducing radical produced during the radiolysis of the solvent are used to reduce metal ions. Recently, very small iron nanoparticles of $2 \mathrm{~nm}$ were synthesized by radiolysis. ${ }^{26}$ Here we show that adjunction of iron to gold enhances remarkably its electrocatalytic properties toward oxygen and proton reduction.

\section{Experimental section}

\section{Chemicals}

Metal salts $\mathrm{KAuCl}_{4}$ from Degussa (purity $\geq 99.8$ ) and/or $\mathrm{FeCl}_{2}$ (purity $\geq 99.8$ ) from Prolabo (metal concentration $1 \times 10^{-3}-2 \times 10^{-3}$ mol $\mathrm{dm}^{-3}$ ) were dissolved with poly(vinylpyrrolydone) (PVP, from Fluka $\mathrm{Mr}=40000)\left(0.1 \mathrm{~mol} \mathrm{dm}^{-3}\right)$ in ethylene glycol (from Prolabo).

\section{Irradiations}

For $\gamma$-radiolysis, the solutions containing the metal complexes were put in small pyrex flasks and were degassed by bubbling 
with nitrogen. The $\gamma$-radiation source was a ${ }^{60} \mathrm{Co}$ panoramic source providing a maximum dose rate of $3.0 \mathrm{kGy} \mathrm{h}^{-1}$.

\section{Characterization techniques}

UV-vis spectra were recorded with a Varian DMS $100 \mathrm{~S}$ spectrophotometer.

TEM was performed on nanoparticles deposited on carbon-coated copper grids using a JEOL JEM 100 CXII transmission electron microscope at accelerating voltage of $100 \mathrm{kV}$ or with a FEI Tecnai equipped with a FEG operating at 200 kV. EDX elemental analysis was performed using an Oxford Instruments system.

The XPS analysis was performed on In foils. Drops of sample were deposited on the foils under glove box and dried under $\mathrm{N}_{2}$ flow. The XPS analyzer was a Thermo Electron ESCALAB 220i-XL. Either a non-monochromatic or a monochromatic X-ray Al K $\alpha$ line was used for excitation. The photoelectrons were detected perpendicularly to the support. A constant analyzer energy mode was used with pass energy of $20 \mathrm{eV}$.

For X-ray observations, samples were transferred to Lindemann glass capillaries (diameter $0.5 \mathrm{~mm}$ ). The diffraction patterns were obtained using Mo $\mathrm{K} \alpha(0.0711 \mathrm{~nm})$ radiation generated by a rotating anode X-ray generator (Rigaku, 7.5 $\mathrm{kW})$. A cylindrical image plate was used to collect the diffraction data and the sample to detector distance was $54.05 \mathrm{~mm}$. Typical exposure was half an hour.

\section{Electrochemical experiments}

For electrochemical experiments, the source, mounting and polishing of the glassy carbon (CC, Le Carbone Lorraine, France) electrodes has been described previously, ${ }^{27}$ as was also described the fabrication technique of the modified electrodes. ${ }^{28}$ Electrodes are fabricated with the assumption that the starting nanoparticle suspensions are homogeneous.

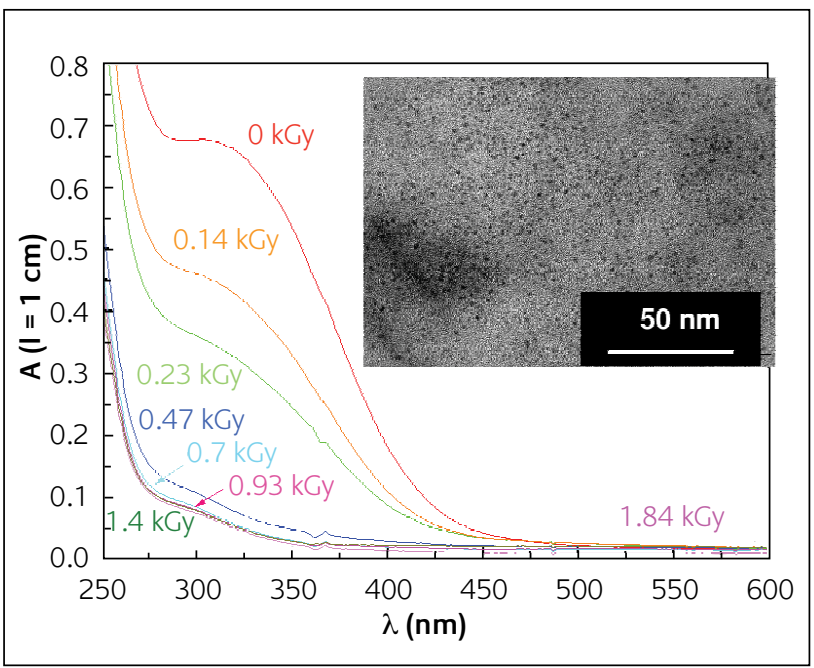

Figure 1

Absorption spectra of a solution containing $10^{-3} \mathrm{~mol} \mathrm{dm}^{-3} \mathrm{Fe}^{\prime \prime}$ and 0.1 mol dm ${ }^{-3}$ PVP in EG irradiated with different doses under $\mathrm{N}_{2}$ atmosphere, dose rate $=2.8 \mathrm{kGy} \mathrm{h} \mathrm{h}^{-1}$. Optical path length $1 \mathrm{~cm}$. Inset: TEM images of Fe nanoparticles obtained after complete reduction
It is also assumed that the deposited amount of nanoparticle is sufficient for a uniform coverage of the electrode surface. The glassy carbon samples had a diameter of $3 \mathrm{~mm}$. The electrochemical set-up was an EG \& C 273 A driven by a PC with the M270 software. Potentials are quoted against a saturated calomel electrode (SCE). The counter electrode was a platinum gauze of large surface area. Pure water was used throughout. It was obtained by passing through a RiOs 8 unit followed by a Millipore-Q Academic purification set. The solutions were deaerated thoroughly for at least 30 minutes with pure argon and kept under a positive pressure of this gas during the experiments. The supporting electrolyte was $0.5 \mathrm{M} \mathrm{H}_{2} \mathrm{SO}_{4}(\mathrm{pH} \mathrm{0.30)}$.

\section{Result and discussion}

In preliminary experiments, pure $\mathrm{Fe}(0)$ and $\mathrm{Au}(0)$ were prepared radiolytically in ethylene glycol (EG) with the presence of poly(vinylpyrrolydone) (PVP). An absorption band with a peak located at $325 \mathrm{~nm}$ due to the Fe"-PVP or Au"'-PVP complexes (Fig. 1 and Fig. 2). Very small and homogenous iron nanoparticles of $2 \mathrm{~nm}$ are obtained by irradiation of Fe"l/PVP solution (Fig. 1 inset). When the irradiated iron solutions are exposed to oxygen, a fast back oxidation of $\mathrm{Fe}(0)$ into $\mathrm{Fe}(\mathrm{II})$ is observed. Fig. 2 presents the UV-visible spectra of a solution containing $\mathrm{Au}(\mathrm{III})$ in $\mathrm{EG}$ in presence of PVP (dose rate $2.8 \mathrm{kGy}$ $\mathrm{h}^{-1}$ ). At the beginning of irradiation, the peak at $325 \mathrm{~nm}$ due to $\mathrm{Au}(\mathrm{III})$ complexes decreases due to their reduction into $\mathrm{Au}(\mathrm{I}),{ }^{29}$ then a plasmon band at $550 \mathrm{~nm}$ appears and increases in intensity (Fig. 2). TEM observation shows faceted $\mathrm{Au}$ nanoparticles (NPs) composed mainly of octahedra (10-15 $\mathrm{nm}$ ) (Fig. 2 inset), a few triangles and rods are also observed.

Owing to their interest for future comparisons, $(\mathrm{Au}+\mathrm{Fe})$ nanoparticles were also synthesized by radiolytic reduction

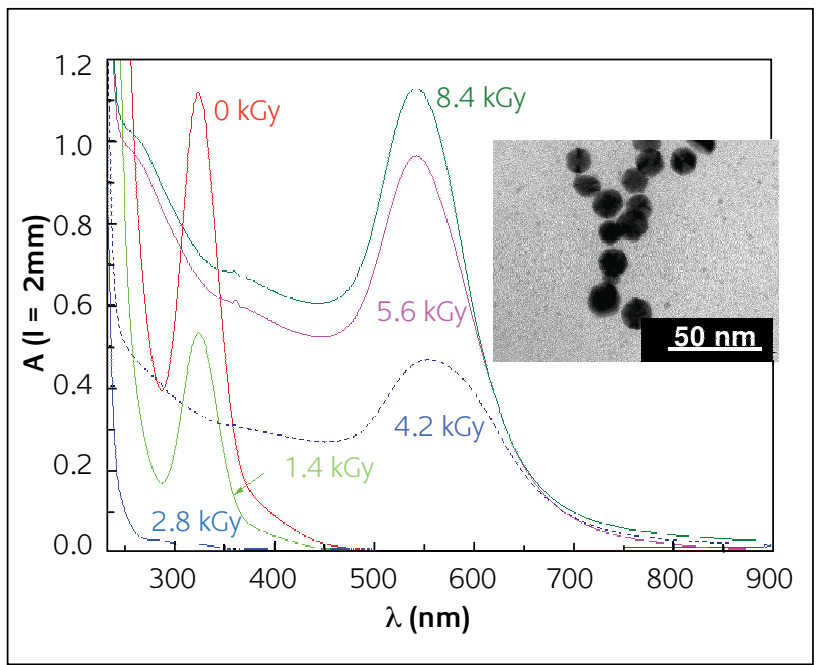

\section{Figure 2}

Absorption spectra of a solution containing $10^{-3} \mathrm{~mol} \mathrm{dm}^{-3} \mathrm{AuCl}_{4}$ and 0.1 $\mathrm{mol} \mathrm{dm}^{-3}$ PVP in EG irradiated with different doses under $\mathrm{N}_{2}$ atmosphere, dose rate $=2.8 \mathrm{kGy} \mathrm{h}^{-1}$. Optical path length $0.2 \mathrm{~cm}$. Inset: TEM images of Au nanoparticles obtained after complete reduction 


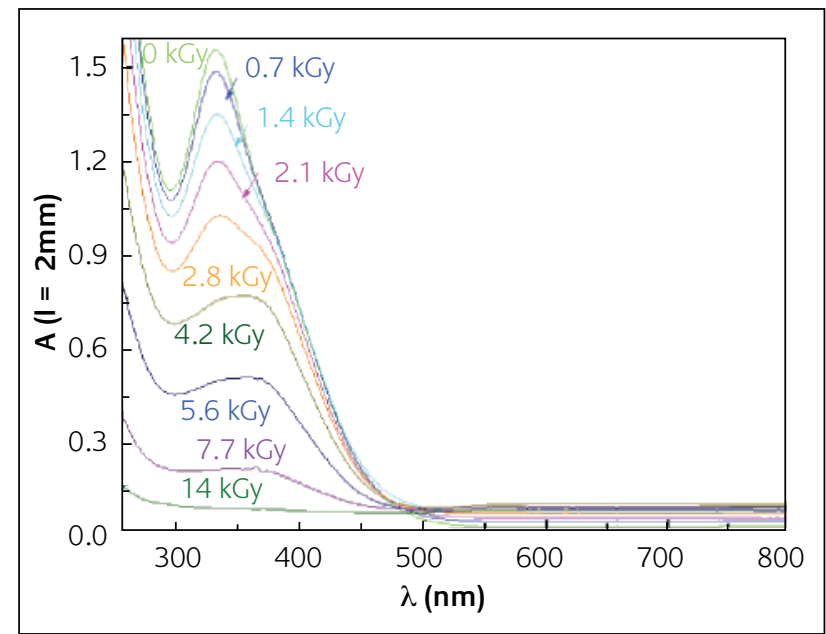

Figure 3

Absorption spectra of a solution containing $10^{-3} \mathrm{~mol} \mathrm{dm}^{-3} \mathrm{AuCl}_{4}, 10^{-3} \mathrm{~mol}$ $\mathrm{dm}^{-3} \mathrm{Fe}^{\prime \prime}$ and $0.1 \mathrm{~mol} \mathrm{dm}^{-3} \mathrm{PVP}$ in EG irradiated with different doses under $\mathrm{N}_{2}$ atmosphere, dose rate $=2.8 \mathrm{KGy} \mathrm{h} h^{-1}$. Optical path length $0.2 \mathrm{~cm}$ of $\mathrm{FeCl}_{2}$ in the presence of preformed $\mathrm{Au}(0)$ nanoparticles with the nominal Fe / Au ratio being 1.

The mixed Au'l'-Fell solutions are slightly yellow before irradiation. Fig. 3 shows the evolution of the UV-visible spectra of a mixed equimolar Au"l'-Fe"l solution in EG (containing PVP) at increasing radiolytic doses. The band at $325 \mathrm{~nm}$ decreases linearly with dose. After complete reduction, the solutions are colorless and no plasmon band of gold is observed. A small light scattering contribution at longer wavelengths is also observed. The spectra of the irradiated solutions do not change upon exposition to air, a feature which differs from that of pure Fe(0) NPs. TEM observations show nanoparticles of $2 \mathrm{~nm}$ as well as a few large and faceted particles (Fig. 4). Energy dispersive $\mathrm{X}$-ray (EDX) analysis attests that the small nanoparticles of $2 \mathrm{~nm}$ are mainly composed of Fe while the large particles are composed of Au with a small amount of Fe (Fig. 4). We performed the XPS measurements on the synthesized nanoparticles. Concerning the $\mathrm{Au} 4 \mathrm{f}_{5 / 2: 7 / 2 \text {, the }}$
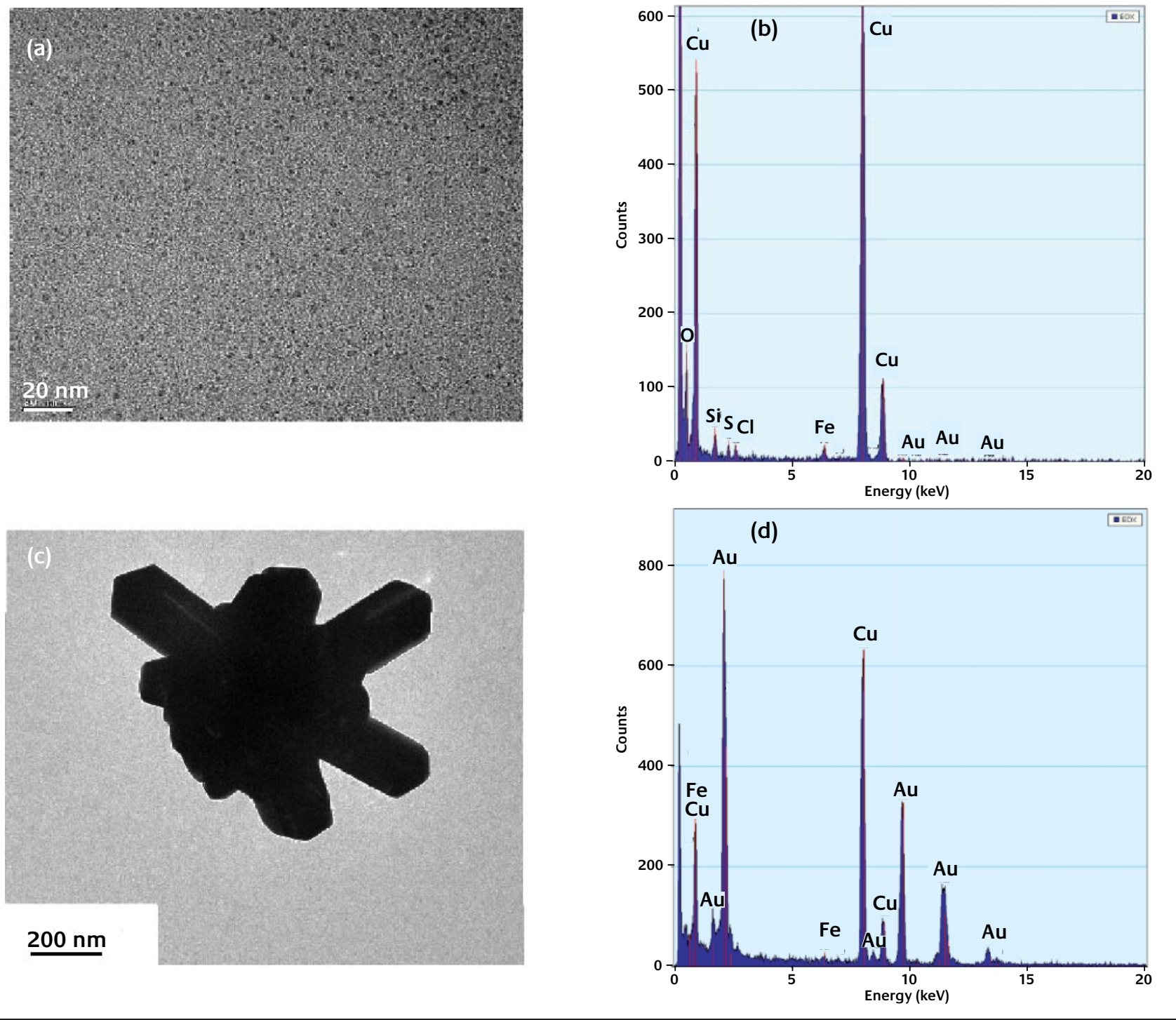

Figure 4

TEM images of nanoparticles obtained by irradiation of a solution containing $10^{-3} \mathrm{~mol} \mathrm{dm}^{-3} \mathrm{AuCl}_{4}^{-}, 10^{-3} \mathrm{~mol} \mathrm{dm}^{-3} \mathrm{Fe}^{\prime \prime}$ and $0.1 \mathrm{~mol} \mathrm{dm}^{-3} \mathrm{PVP}$ in EG (dose $=14.0 \mathrm{kGy}$, dose rate $=2.8 \mathrm{kGy} \mathrm{h}^{-1}$ ) and the corresponding EDAX analysis. Small particles of $2 \mathrm{~nm}$ (rich in Fe) (Fig. $\left.4 a-b\right)$ as well as a few large rods and faceted particles (rich in Au and containing a small amount of Fe) (Fig. 4c-d) are obtained 

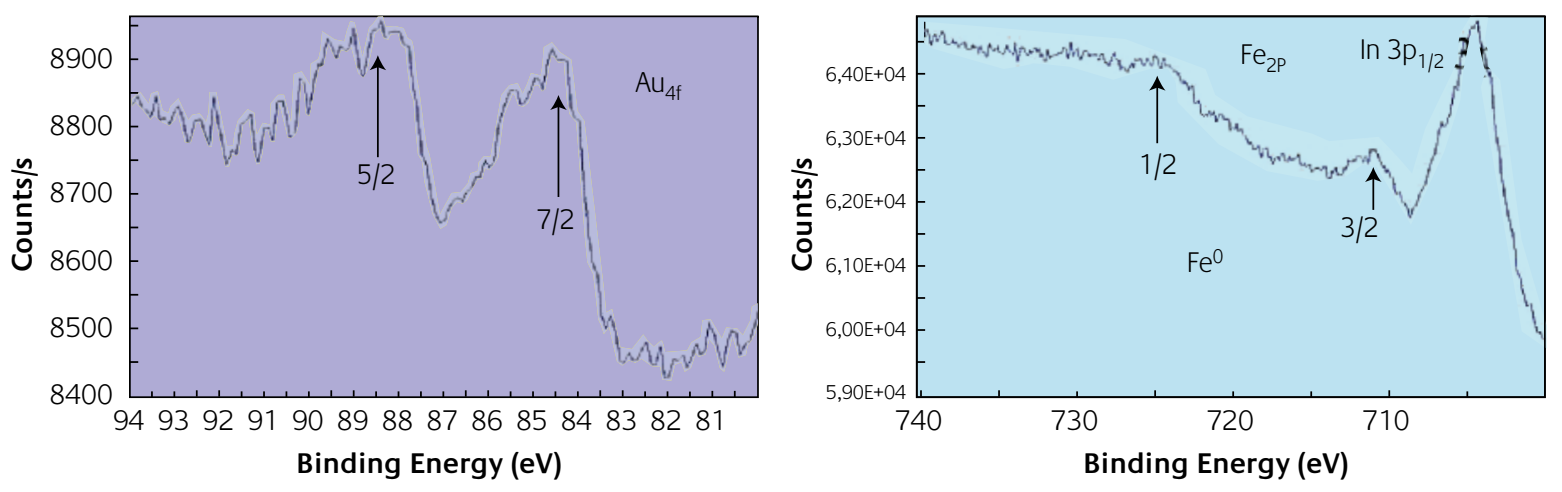

\section{Figure 5}

XPS spectra of the nanoparticles obtained by irradiation of a solution containing $10^{-3} \mathrm{M} \mathrm{FeCl}_{2} / 10^{-3} \mathrm{KAuCl}_{4}$ and $0.1 \mathrm{M} \mathrm{PVP}$ (dose $4.8 \mathrm{kGy}$ ) and deposited on indium foils. The peak around $704 \mathrm{eV}$ is due to In $3 p_{1 / 2}$

peaks show a specific high energy broadening that suggests the contribution of different sites: the low component at about $84 \mathrm{eV}$ is probably due to $\mathrm{Au}^{0}$, the component at highest energy $+\Delta<0.5-1 \mathrm{eV}>$ is original and could be interpreted as resulting from Au-Fe bounding (Fig. 5). Concerning the Fe $2 p$ spectrum (Fig. 5), it differs from that of pure Fe NPs, that is a $\mathrm{Fe}_{2} \mathrm{O}_{3}$ configuration. For the Au-Fe system, the energy distribution slightly differs suggesting that iron in Au-Fe NPs is less sensitive to oxidation.

Mixed solutions with other $\left[\mathrm{Au}^{\prime \prime \prime}\right] /\left[\mathrm{Fe} \mathrm{E}^{\prime \prime}\right]$ ratios $(1 / 3$ and $1 / 1)$ were irradiated under the same conditions. After complete reduction, the irradiated solutions are colorless and again no plasmon band is obtained. TEM images show $2 \mathrm{~nm}$ nanoparticles as well as a very few large rods and faceted particles.

XRD measurements on Au-Fe nanoparticles obtained at various Au/Fe molar ratios were performed. For the nanoparticles synthesized with the initial ratio $\mathrm{Au}^{\prime \prime \prime} / \mathrm{Fe}^{\| \prime}=3 / 1$, five characteristic diffraction lines corresponding to the (111), (200), (220), (311) and (222) planes of a fcc lattice are found, at $2 \theta=17.28^{\circ}, 20.03^{\circ}, 28.73^{\circ}, 33.81^{\circ}$ and $35.30^{\circ}$ respectively (using Mo radiation $(\lambda=0.0711 \mathrm{~nm})$ ). This structure is very close to the one of bulk gold.

For Au-Fe nanoparticles obtained from the initial ratios ( $A u^{\prime \prime \prime} / F e^{\prime \prime}=1 / 1$ and $A u^{\prime \prime \prime} / F e^{\prime \prime}=1 / 3$ ), no sharp Bragg peaks are recorded. This indicates that most of the nanoparticles are quite small. Probably, the amount of large NP's rich in gold is too small to detect the associated sharp Bragg peaks. Note that the (200) and (220) planes of fcc Au or Au-Fe nanoparticles are close to those for the (110) and (200) planes of bulk bcc Fe. ${ }^{19}$

The nanoparticles can be easily extracted by centrifugation even for the small size NPs because of a high and efficient coverage of the NPs by the PVP. The electro-catalytic properties of these Fe-Au nanoparticles have been evaluated by cyclic voltammetry.

Typical results are described for an electrode fabricated by depositing a few $\mu$ l of Au-Fe (50:50) nanoparticles suspension (obtained from the equimolar solution $\mathrm{Au}^{\prime \prime \prime} / \mathrm{Fe} \mathrm{F}^{\mathrm{I}}=1$ ) in water on a polished glassy carbon (CC) surface, covering with $6 \mu$ l of 5 wt \% Nafion solution and letting dry in the air at room temperature. Figure 6 shows the cyclic voltammetry response for such an electrode in $0.5 \mathrm{M} \mathrm{H}_{2} \mathrm{SO}_{4}$ solution ( $\mathrm{pH} 0.30$ ). Two main features are observed in the potential domain extending from $+1.52 \mathrm{~V}$ to $-0.300 \mathrm{~V}$ vs SCE: the formation and reduction of gold oxides in the high potential domain just before oxygen evolution; and the proton reduction and hydrogen oxidation in the negative potential domain. This voltammetric pattern remains stable upon continuous potential cycling, with a slight tendency of the proton reduction process to shift in the positive potential direction during the first several cycles. Observation of such macroscopic stability and the analogy with the recent successful use of Pd-Fe NPs for oxygen reduction in acid medium ${ }^{30}$ constitute the basis for further study of the Au-Fe electrode. Figure 7 compares the hydrogen evolution reaction (HER) in $0.5 \mathrm{M}$ $\mathrm{H}_{2} \mathrm{SO}_{4}$ for four electrodes prepared with the same procedure, using Au-Fe (50:50), (Au + Fe) nanoparticles, pure Fe and pure Au nanoparticles respectively. For this comparison, it is



\section{Figure 6}

Representative cyclic voltammogram observed upon cycling a glassy carbon electrode modified by Fe-Au (50:50) nanoparticles in a $0.5 \mathrm{M}$ $\mathrm{H}_{2} \mathrm{SO}_{4}(\mathrm{pH}=0.30)$ solution in the absence of dioxygen. The reference electrode was a saturated calomel electrode (SCE); the scan rate was $10 \mathrm{mV} \mathrm{s}^{-1}$. For further details, see text 


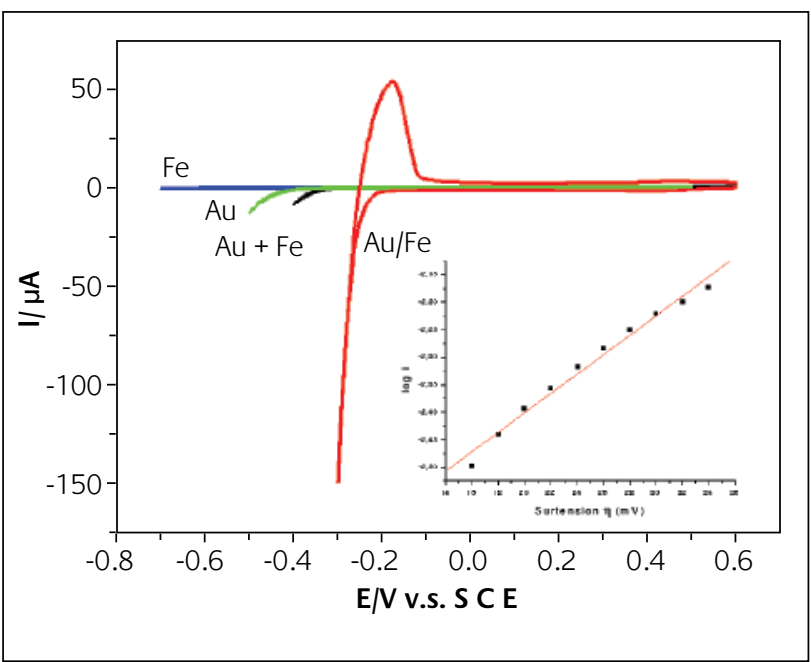

Figure 7

Representative cyclic voltammograms restricted to the hydrogen evolution reaction (HER) potential domain in a $0.5 \mathrm{M} \mathrm{H}_{2} \mathrm{SO}_{4}(\mathrm{pH}=0.30)$ solution in the absence of dioxygen. The glassy carbon electrodes were modified respectively with Fe-Au (50:50) nanoparticles (curve A), (Au + $\mathrm{Fe}$ ) nanoparticles, pure Au and pure Fe nanoparticles. Inset: Tafel polarisation line for the HER corresponding to the curve observed with the FeAu (50:50) electrode. The reference electrode was a saturated calomel electrode (SCE); the scan rate was $10 \mathrm{mV} \mathrm{s}^{-1}$, except for the Tafel analysis for which the scan rate was $2 \mathrm{mV} \mathrm{s}^{-1}$. For further details, see text

worth reminding that spherical nanoparticles were obtained, except for Au nanoparticles (NPs) composed mainly of octahedral, a few triangles and rods. However, in a first approximation, the shapes and sizes of the nanoparticles, the electrochemical behaviours of which will be compared, are not the primary parameters of the present study. In addition, even though iron Pourbaix diagrams indicate clearly the instability of Fe in this supporting electrolyte, the comparison

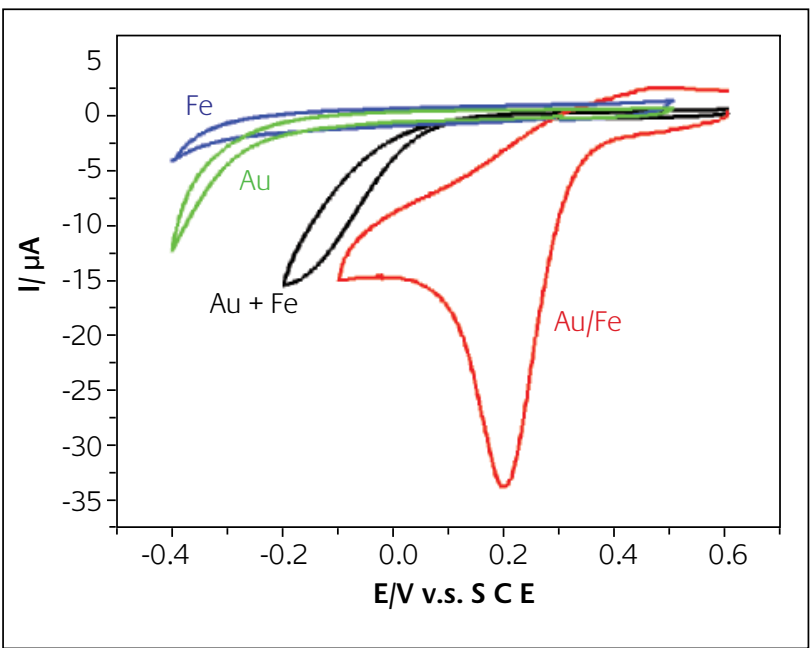

\section{Figure 8}

Representative cyclic voltammograms restricted to the oxygen reduction reaction (ORR) potential domain in a $0.5 \mathrm{M} \mathrm{H}_{2} \mathrm{SO}_{4}(\mathrm{pH}=0.30)$ solution saturated with dioxygen. The glassy carbon electrodes were modified respectively with Au-Fe (50:50) nanoparticles, (Au + Fe) nanoparticles, pure Au and pure Fe nanoparticles. The reference electrode was a saturated calomel electrode (SCE); the scan rate was $10 \mathrm{mV} \mathrm{s}^{-1}$. For further details, see text is useful in ruling out the possibility that the observed HER be due to any iron compound alone. Among interesting conclusions, it must be noted that the ( $\mathrm{Au}+\mathrm{Fe}$ ) system is less efficient than the Au-Fe system. In short, the superiority of the bimetallic Au-Fe system for carrying out the HER is obvious. A voltammogram run at a scan rate of $2 \mathrm{mV} \mathrm{s}^{-1}$ was selected for Tafel analysis $(\eta=a+b$ logi, where $\eta$ is the applied overpotential, b the Tafel slope) with the current density i expressed in ampere per unit of electrode geometric surface, because reliable measurement of electrode true surface area is seldom possible. Analysis of the low current density domain gives a straight line (see Figure 7 , inset) with a correlation coefficient of $R=0.992$ and an exchange current density $i_{0}$ in $\mathrm{A} \mathrm{cm}^{-2}, \log i_{0}=-2.75 \pm 0.02$ with a Tafel slope of about - $57 \mathrm{mV}$ for the Au-Fe (50:50) electrode. These characteristics are in the range obtained for the best metallic electrodes; for example, logi $=-3.34$ to - 2.63 for Pt with slopes ranging from - 30 to $-120 \mathrm{mV} .^{32,33}$ This comparison underscores the significantly high current density achieved with the Au-Fe electrode. The Au-Fe (75:25) and $\mathrm{Au}-\mathrm{Fe}$ (25:75) electrodes were also studied. For these electrodes, including the Fe-Au (50:50) electrode, the HER signal moves steadily in the positive potential direction upon cycling before reaching a final position. At present, there is no clue indicating whether this observation should be attributed to a modification of surface composition, to a mere rearrangement of surface atoms, to both or to other possibilities. At least, it is worth noting, for stabilised electrodes, that the Au-Fe (50:50) composition proved more efficient, in terms of potential location for the HER, than the Au-Fe (75:25) and Au-Fe (25:75) proportions. Typically, for a current density of $20 \mathrm{~mA} \mathrm{~cm} \mathrm{~cm}^{-2}$, the potentials measured against the SCE are - $0.330 \mathrm{~V}$ for the Fe-Au (50:50) electrode,

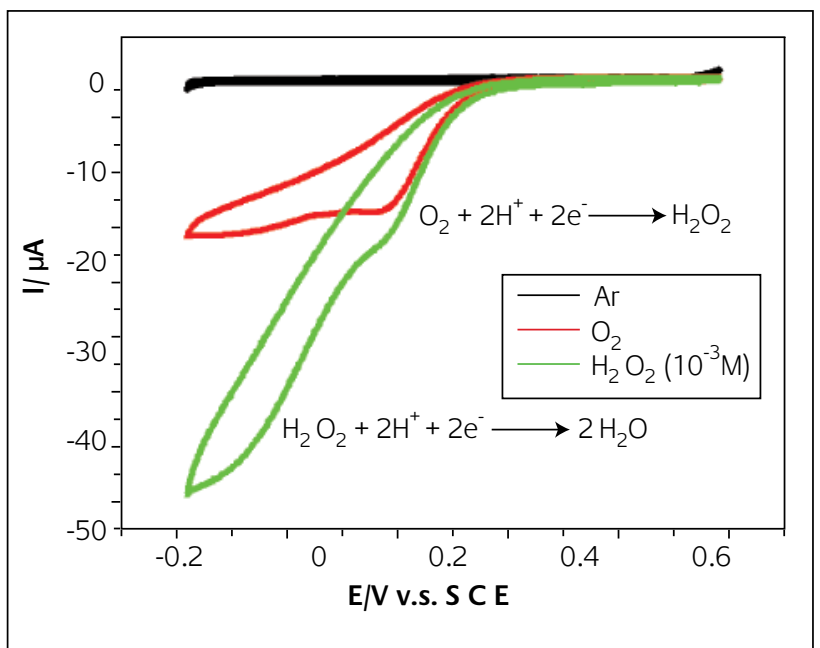

Figure 9

Cyclic voltammogram showing the electrocatalytic reduction of dioxygen in a $0.5 \mathrm{M} \mathrm{H}_{2} \mathrm{SO}_{4}(\mathrm{PH}=0.30)$ solution saturated with $\mathrm{O}_{2}$ on the glassy carbon electrode modified by $\mathrm{Au}$ - Fe (75:25) nanoparticles as described in the text. The reference electrode was a saturated calomel electrode (SCE); the scan rate was $10 \mathrm{mV} \mathrm{s}^{-1}$. For further details, see text 
- $0.470 \mathrm{~V}$ for the Fe-Au $(75: 25)$ electrode and $-0.580 \mathrm{~V}$ for the Fe-Au (25:75) electrode respectively.

The same four electrodes, including Au-Fe (50:50), $(\mathrm{Au}+\mathrm{Fe})$ nanoparticles, pure Fe and pure Au nanoparticles respectively, were also tested for their efficiency in the electrocatalytic oxygen reduction reaction (ORR) in $0.5 \mathrm{M}$ $\mathrm{H}_{2} \mathrm{SO}_{4}$. Figure 8 shows the corresponding cyclic voltammograms. The higher efficiency of the Au-Fe system for the ORR parallels that observed for the HER. In short, the bimetallic Au-Fe system appears as more efficient than any of the two pure metals and the $(\mathrm{Au}+\mathrm{Fe})$ system for the electrocatalytic reduction of dioxygen in acidic medium. For a more detailed study of this process, the results for Au-Fe (75:25), Au-Fe (50:50) and Au-Fe (25:75) electrodes were compared. The best observations were made with the Au-Fe (75:25) electrode and are shown in Figure 9. With a scan rate of $2 \mathrm{mV} \mathrm{s}^{-1}$ or $10 \mathrm{mV} \mathrm{s}^{-1}$, the oxygen reduction is featured by two reduction processes. Typically, the first reduction peak potential is located at $+0.070 \mathrm{~V}$ and the second one roughly at $-0.110 \mathrm{~V}$ at a scan rate of $10 \mathrm{mV} \mathrm{s}^{-1}$. The two waves are merged at a scan rate of $100 \mathrm{mV} \mathrm{s}^{-1}$. The first step is associated with the two-electron reduction of oxygen into hydrogen peroxide and the second step features further reduction of this peroxide into water. This interpretation is supported by the observation that addition of $\mathrm{H}_{2} \mathrm{O}_{2}$ to the solution enhances the current intensity at the potential location of the second wave obtained with $\mathrm{O}_{2}$ alone. Actually, bulk Au electrodes are known to reduce oxygen to $\mathrm{H}_{2} \mathrm{O}_{2}$ through a single voltammetric wave. Therefore, observation of two waves indicates a remarkable activity of the electrode material for the ORR. As a matter of fact, a recent example of such behaviour observed for Au nanoparticles electrodeposited on Au electrodes was published as "an extraordinary electrocatalytic reduction of oxygen" by El-Deab and Ohsaka. ${ }^{34}$ For the two other electrodes, Au-Fe (50:50) and Au-Fe (25:75), a single oxygen reduction wave is observed down to the HER potential location whatever the scan rate. It is worth noting that the activity of the Au-Fe (50:50) and Au-Fe (25:75) electrodes is high compared to literature values. Typically, the reduction peak potential was measured at $+0.200 \mathrm{~V}$ vs SCE at a scan rate of $10 \mathrm{mV} \mathrm{s}^{-1}$ and at $-0.02 \mathrm{~V}$ vs SCE at $100 \mathrm{mV} \mathrm{s}^{-1}$ for the Au-Fe (50:50) electrode. A value of + $0.088 \mathrm{mV}$ was obtained for the Au-Fe (25:75) at $10 \mathrm{mV} \mathrm{s}^{-1}$. Tentatively, it can be suggested that such remarkable behaviours should be attributed both to the intrinsic properties of the Au-Fe system. The two reduction steps of $\mathrm{O}_{2}$ on $\mathrm{Au}$ nanoparticles electrodeposited on Au electrodes were observed at + 0.050 $\mathrm{V}$ and $-0.250 \mathrm{~V}$ vs SCE respectively, at a scan rate of $100 \mathrm{mV}$ $\mathrm{S}^{-1}$ in $0.5 \mathrm{M} \mathrm{H}_{2} \mathrm{SO}_{4}{ }^{34}$. The fairly good match of the single reduction peak potential observed for oxygen reduction on the Au-Fe (25:75) electrode with that of the first reduction step on Au-Fe (75:25) material suggests the former electrode to produce hydrogen peroxide. No simple interpretation can be offered for oxygen reduction on the Au-Fe (50:50) with a reduction peak potential located more than $0.1 \mathrm{~V}$ positive of the value observed for Au-Fe (25:75) electrode. Preparative and mechanistic studies are still necessary to completely understand the reduction process of oxygen on these series of electrodes and determine the associated kinetic parameters. Such complex pattern was reported, for example, in the study of $\mathrm{O}_{2}$ reduction on rotating thin-film Au electrodes in $0.5 \mathrm{M} \mathrm{H}_{2} \mathrm{SO}_{4}$, where the number of electrons consumed per molecule of $\mathrm{O}_{2}$ increased from 2 at the foot of the single polarisation wave to more than two at more negative potentials, thus indicating the further reduction of the peroxide formed by the reduction of $\mathrm{O}_{2} \cdot{ }^{35}$ Finally, the final product of oxygen reduction in acid medium by the Fe-Au system will depend on the composition of the irradiated solution. Work in progress will consider this aspect.

\section{Conclusion}

Radiolytic reduction of mixed Au"l'/Fe" EG solutions led to two kind of particles: $2 \mathrm{~nm}$ Fe rich nanoparticles as well as large and faceted (a few tens of $\mathrm{nm}$ ) gold rich particles containing a small amount of iron. This Au-Fe system shows promise for use as efficient cathodes in the reduction of proton and of oxygen. Work in progress will consider the long term stability of these materials in different supporting electrolytes and their ability to trigger various electrocatalytic processes.

\section{Acknowledgements}

The authors thank Jackie Vigneron (Institut Lavoisier, Université Versailles Saint Quentin-en-Yvelines) for assistance in XPS experiments and Patricia Beaunier (Laboratoire de Réactivité des Surfaces, Université Paris VI) for additional TEM observations.

\section{About the authors}

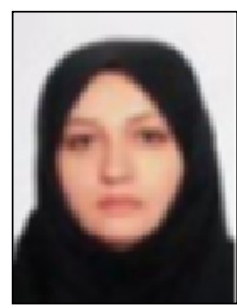

Malaknaz Mirdamadi Esfahani is a PhD student in the Laboratory of Physical Chemistry (LCP) at the Paris-Sud University. Her research activities are fast kinetics and electron relaxation measurements in solution by pulse radiolysis, synthesis of metal nanoparticles in solution and their applications in electro catalysis.

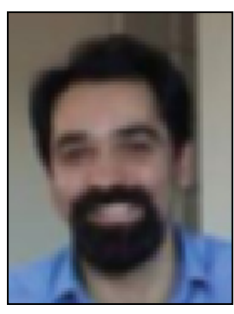

Mehran Mostafavi is Professor of Physical Chemistry at Paris-Sud University and the head of the Laboratoire de Chimie Physique of CNRS at Orsay. One of his research interests is the mechanism of metal and semiconductor nano-clusters growth induced by irradiation in solution. 


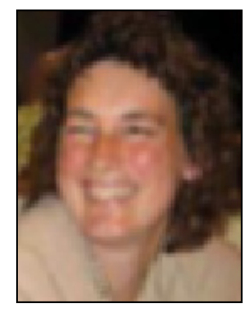

Patricia J. Kooyman is assistant professor in catalysis engineering at Delft University of Technology since 2002. Her activities are focused on structure-activity relations in heterogeneous catalysts (zeolites and mesoporous materials, sulphides, metal nanoparticles) and include state-of-theart transmission electron microscopy.

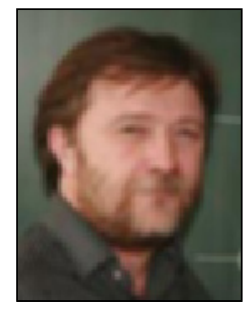

Arnaud Etcheberry is a CNRS (Centre National de Recherche Scientifique) researcher and the second Head of The Institut Lavoisier of Versailles. He is also the leader of the Electrochemistry and Physical Chemistry at the Interfaces group. His research interests focus on surface analysis by photoelectron spectroscopy and Auger electrons, noble metal and semiconductor surfaces, metal and semiconductor electrochemistry, electrochemistry on functionalized Pt nanoparticles, electrocatalysis and electrodeposition.

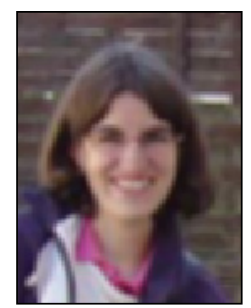

Mariane Imperor got a $\mathrm{PhD}$ in physics in 1992 at Paris-Sud University, Orsay. She is a researcher at the CNRS since 1992. She is working in the X-ray team from the Laboratoire de Physique des Solides in Orsay at the Paris-Sud University. Her research interests concern the structure of complex fluids, liquid-crystals and mesoporous materials, using mainly $\mathrm{X}$-ray scattering experiments.

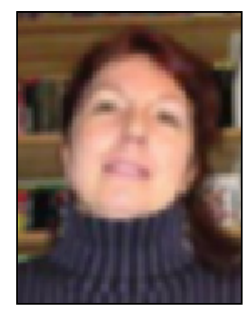

Hynd Remita is a CNRS researcher since 1994. She is working in the Laboratoire de Chimie Physique in Orsay at the Paris-Sud University. Her research interests focus on radiolysis, metal nanoparticles and nanomaterials, nucleation and growth processes, fuel cells and photocatalysis.

Dr Bineta Keita (Directeur de Recherche in the French CNRS) and Prof. Louis Nadjo are senior researchers. Their work is focused on electrochemistry and electrocatalysis.

\section{References}

1 G.G. Nunes, R.C.R. Bottini, D.M. Reis, P.H.C. Camargo, D.J. Evans, P.B. Hitchcock, G.J. Leigh, E.L. Sa, J.F. Soares, Inorg. Chim. Acta, 2004, 357, 1219

2 M. Haruta, J. New Mat. Electrochemical Syst., 2004, 7, 163

3 C.J. Zhong, M.M. Maye Adv. Mater. 2001, 13, 1507
4 D.T. Thompson, Nanotoday, 2007, 2, 40

5 J.L. Fernandez, D.A. Walsh, A.J. Bard, J. Am. Chem. Soc., 2005, 127, 357

6 K.A. Friedrich, F. Henglein, U. Stimming, W. Unkauf, Electrochim. Acta, $2000,45,3283$

7 T.J. Schmidt, Z. Jusys, H.A. Gasteiger, R.J. Behm, U. Endruschat, H.J. Bonnemann, Electroanal. Chem. 2001, 501, 132

8 T.J. Schmidt, V. Stamenkovic, N.M. Markovic, P.N. Ross Jr., Electrochim. Acta, 2003, 48, 3823

9 B.B. Blizanac, M. Arenz, P.N. Ross, N.M. Markovic, J. Am. Chem. Soc., 2004, 126, 10130

10 G. Tremiliosi-Filho, E.R. Gonzalez, A.J. Motheo, E.M. Belgsir, J.-M. Léger, C. Lamy, J. Electroanal. Chem., 1998, 444, 31

11 Z. Borkowska, A. Tymosiak-Zielinska, G. Shul, Electrochim. Acta, 2004, 49, 1209

12 J. Luo, P.N. Njoki, Y. Lin, L. Wang, C.J. Zhong, Electrochem. Commun., 2006, 8, 581

13 M.S. El-Deab, T. Osaka, Electrochim. Acta, 2002, 47, 4255

14 C. Mihut, C. Descrome, D. Duprez, M.D. Amiridis, J. Catal., 2003, 212, 125

15 P. Hernandez-Fernandez, S. Rojas, P. Ocon, J.L. Gomez de la Fuente, J. San Fabian, J. Sanza, M.A. Pena, FJ. Garcia-Garcia, P. Terreros, J.L.G. Fierro, J. Phys. Chem. C, 2007, 111, 2913

16 K. Sato, B. Bian, Y. Hirotsu, Jpn. J. Appl. Phys. Part 2, 2002, 41, L1

17 D.L. Lu, K. Domen, K.I. Tanaka, Langmuir, 2002, 18, 3226

18 Y.P. Lee, R. Gontarz, J.Y. Rhee, Phys. Rev. B: Condes. Matter.Mater. Phys., 2003, 67, 104424

19 I.C. Chang and D.H. Chen, Adv. Func. Mater., 2007, 17, 1311

20 J. Belloni, M. Mostafavi, H. Remita, J.L. Marignier, M.O. Delcourt, New. J. Chem., 1998, 22, 1239

21 J. Belloni, Catal. Today, 2006, 113, 141

22 M. Tréguer, C. de Cointet, H. Remita, J. Khatouri, M. Mostafavi, J. Amblard, J. Belloni \& R. De Keyser, J. Phys. Chem. B, 1998, 102, 4310

23 H. Remita, A. Etchebery, J. Belloni, J. Phys. Chem. B, 2003, 107, 31

24 H. Remita, I. Lampre, M. Mostafavi, E. Balanzat, S. Bouffard, Radiat. Phys. Chem., 2005, 72, 575

25 H. Remita, J. Khatouri, M. Tréguer, J. Amblard, J. Belloni, Z. Phys. D, 1997, 40, 127

26 G.R. Dey, H. Remita, M. Mostafavi, Chem. Phys. Lett., 2006, 431, 83

27 B. Keita, L. Nadjo, J. Electroanal. Chem., 1988, 243, 87

28 B. Keita, G. Zhang, A. Dolbecq, P. Mialane, F. Sécheresse, F. Miserque, L. Nadjo J. Phys. Chem. C, 2007, 111, 8145

29 E.Gachard, H. Remita, J. Khatouri, J. Belloni, B.Keita, L.Nadjo, New. J. Chem., 1998, 1257

30 M-H. Shao, K. Sasaki, R.R. Adzic, J. Am. Chem. Soc., 2006, 128, 3526

31 B. Beverskog, I. Puigdomenech, Corrosion Science, 1996, 38, 2121

32 a) S. Trasatti, J. Electroanal. Chem. 1972, 39, 163; b) J. Norskov, T. Bligaard, A. Logadottir, J.R. Kitchin, J.G. Chen, S. Pandelov, U. Stimming, J. Electrochem. Soc., 2005, 152, 323

33 M. Enyo, B.E. Conway, J.O’M. Bockris, in E. Yeager, S.V.M. Khan, R.E. White (Eds), Comprehensive Treatise of Electrochemistry, Vol. 7, Plenum Press, New York, 1983, p. 241

34 M. S. El-Deab, T. Ohsaka, Electrochem. Commun., 2002, 4, 288

35 A. Sarapuu, K. Tammeveski, T.T. Tenno, V. Sammelselg, K. Konturri, D.J. Schiffrin, Electrochem. Commun. 2001, 3, 446 